\title{
ANÁLISE DO PREGÃO ELETRÔNICO E PRESENCIAL NA UNIVERSIDADE ESTADUAL DE MATO GROSSO DO SUL
}

\author{
ANALYSIS OF ELECTRONIC AND PRESENCIAL PREGÃO IN THE STATE \\ UNIVERSITY OF MATO GROSSO DO SUL
}

\author{
Simone de Oliveira Rocha Cavalcante \\ Universidade Estadual do Mato Grosso do Sul, Dourados, MS. Brasil. \\ E-mail: srochacavalcante@gmail.com \\ Lucimara Inácio do Prado da Silva \\ Universidade Estadual do Mato Grosso do Sul, Dourados, MS. Brasil. \\ E-mail: lucimara.inacioprado@gmail.com \\ Moisés Centenaro \\ Universidade Estadual do Mato Grosso do Sul, Dourados, MS. Brasil. \\ E-mail: centenaro.uems@gmail.com \\ Carlos Otávio Zamberlan \\ Universidade Estadual do Mato Grosso do Sul, Dourados, MS. Brasil. \\ E-mail: otaviozamberlan@gmail.com
}

Recebido em: 16.02.2017 - Aceito em: 05.03.2017

\section{RESUMO}

O presente artigo tem como objetivo fazer uma análise comparativa, por meio de um estudo de caso, na Universidade Estadual de Mato Grosso do Sul, entre o pregão eletrônico e presencial. A pesquisa foi realizada, tendo como base os valores de referência constante do edital e o valor final licitado. $O$ estudo visa verificar a economicidade em cada modalidade com foco no preço, no tempo decorrente a contar da inicialização ao término de cada processo em cada modalidade, o qual fora considerado em dias corridos identificando em quais modalidades são realizados maiores números de contratações com empresas da região de Dourados-MS, do estado de Mato Grosso do Sul ou de outras localidades. Como metodologia foi utilizado o estudo de caso, dos Pregões Presencias e eletrônicos realizados no ano de 2013, afim de analisar nos processos selecionados, o tempo, preço e contratação local. O estudo demonstra ainda as diferenças básicas procedimentais entre as duas modalidades e ao final apresenta os resultados alcançados, os quais foram distintos do esperado uma vez que nos processos analisados, a modalidade eletrônica não apresentou maior eficiência com relação a maior economicidade, agilidade e nem com relação a contratação local.

PALAVRAS-CHAVE: Pregão eletrônico, Pregão Presencial, Tempo, Preço, Contratação Local. 


\section{ABSTRACT}

This article has the objective to make a comparative analysis through a case study at the State University of Mato Grosso do Sul, between electronic trading and face. The research was conducted, based on the constant reference values of the announcement and the final amount bid. The study aims to verify the economic viability of each mode focusing on price, time elapsed from the start to the end of each process in each mode, which was considered in calendar days identifying in which arrangements are made larger numbers of contracts with companies Dourados-MS, the state of Mato Grosso do Sul or other locations. The methodology used was the case study, the Presencias and electronic trading sessions conducted in 2013 in order to analyze the selected processes, time, price, and local hiring. The study also demonstrates the basic procedural differences between the two modes and the end presents the results achieved, which were different than expected since the analyzed cases, the electronic mode did not show greater efficiency with respect to greater economic efficiency, agility, and not with regarding local hiring.

KEYWORDS: Electronic Trading, Trading Face, Time, Price, Location Hiring.

\section{INTRODUÇÃO}

Ultimamente a administração pública tem sido uma das maiores consumidoras de produtos e serviços no Brasil e o recurso público deve ser efetivamente aplicado. Para que ele seja utilizado da melhor maneira possível, em prol do interesse público, de modo que não ocorram desperdícios, com despesas desnecessárias, bem como seja garantida a isonomia entre os fornecedores, por meio de iguais condições de participação, foi instituída a licitação, a fim de regulamentar as compras públicas.

A promulgação da Lei 8666/93 teve como principal mote a finalidade de regular as compras na gestão pública, com o intuito de garantir a isonomia entre os participantes dos procedimentos licitatórios realizados pelos entes e unidades da federação, bem como com a finalidade de que a Administração Pública adquirisse para si a proposta mais vantajosa.

Como muito bem discorre Gasparini (1955), a licitação é o procedimento pelo qual a Administração Pública visa selecionar a melhor proposta de modo que seja a mais vantajosa, com melhor preço, com igualdade de condições de participação aos licitantes, na oportunidade transcreve-se o texto do autor citado: 
[...] De fato a licitação visa proporcionar, em primeiro lugar, às pessoas a ela submetidas, a obtenção da proposta mais vantajosa (a que melhor atende, especialmente, em termos financeiros aos interesses da entidade licitante), e, segundo lugar, dar igual oportunidade aos que desejam com essas pessoas contratar. [...] (GASPARINI, 1995, p. 471)

Nota-se que o principal objetivo da lei é com relação ao preço de modo que ela determina que a obtenção da proposta mais vantajosa se refere essencialmente a esse fator. Todavia, deve também ser levado em consideração a qualidade do que se adquire, mas isso já está muito mais ligado a especificação do produto ou serviço a ser contratado do que a legislação pertinente.

Com vistas a melhorar as contratações realizadas pelo Governo foi instituída a Lei 10.520/2002, a qual trouxe uma nova modalidade de licitação, denominada pregão, que no Governo Federal foi regulamentado pelos Decretos n. 3555/2000 e n. 5.450/2005, o segundo veio regulamentando o pregão na forma eletrônica e, coube aos estados e municípios regulamentarem por meio de suas legislações locais.

De acordo com Crecencio (2002), a licitação é o procedimento utilizado pela Administração Pública para estabelecer normas gerais para contratos administrativos, pertinentes a obras e serviços, inclusive de publicidade, compras, alienações e locações no âmbito dos poderes da União, dos Estados, do Distrito Federal e dos Municípios. Encontram-se subordinados também a esta lei os fundos especiais, as autarquias, as fundações, as empresas públicas, as sociedades de economia mista e demais entidades controladas direta ou indiretamente pela União, Estados, Distrito Federal e pelos Municípios.

A licitação tem por finalidade, dentre outras coisas, garantir o princípio da isonomia e selecionar a proposta mais vantajosa para a Administração, em conformidade com os princípios constitucionais estabelecidos da legalidade, impessoalidade, moralidade, publicidade e eficiência. Furtado (2007) enfoca muito bem isso, quando afirma que a licitação busca garantir a observância do principio constitucional da isonomia e a selecionar a proposta que apresenta maior vantagem para a Administração Pública, a qual será processada e julgada em estrita conformidade com os princípios legais.

Frente a essas constatações, o presente artigo objetiva comparar o pregão presencial e o eletrônico, suas principais diferenças e, por meio de um estudo de caso, através de análise prática, realizada na Universidade Estadual de Mato Grosso do Sul, no ano de 2013, verificar as diferenças com relação ao tempo, preço e contratação local entre essas duas modalidades.

A finalidade do artigo é também verificar quais das duas modalidades desempenham melhor os princípios propostos à licitação, com relação à melhor proposta, 
lembrando que o foco é o melhor preço. Não se pretende aqui analisar a qualidade dos bens e serviços adquiridos e nem se eles atendem aos fins a que foram propostos e, sim o quanto a modalidade consegue influenciar no desenvolvimento local.

A metodologia aplicada foi uma análise descritiva e amostral, por meio de um estudo de caso realizado no âmbito da Universidade Estadual de Mato Grosso do Sul, em licitações ocorridas no ano de 2013, bem como um levantamento bibliográfico acerca do tema.

Além desta Introdução este artigo foi organizado de modo que no referencial teórico tenha um levantamento sobre o desenvolvimento econômico local, bem como o desencadeamento do desenvolvimento por meio da Teoria das Instituições e a inovação como peça primordial para o desenvolvimento onde é abordada a Teoria Schumpeteriana. Na sequência tratou-se de licitações, por meio de uma abordagem teórica bem como foram relacionadas as principais diferenças procedimentais entre pregão eletrônico e presencial. A outra seção trata da metodologia utilizada e como a pesquisa se deu por meio de estudo de caso, e já partindo para a finalização foram apresentados os dados e os resultados obtidos e por fim as Considerações finais e as referências bibliográficas utilizadas.

\section{REFERENCIAL TEÓRICO}

Neste artigo serão abordados os teóricos que trazem em suas teorias a importante participação estatal como fomentador do desenvolvimento, por exemplo, Lima e Simões (2010) afirmam que o plano de desenvolvimento deve ser entendido como um programa estratégico para intervir nas forças propulsoras de mercado e, desse modo, condicioná -las a impulsionar o progresso social e, o Estado de certo modo acaba assumindo a função de estimular o desenvolvimento, de modo a aumentar o padrão de vida da população.

A idéia de que o crescimento é necessariamente desequilibrado, foi compartilhada por outro autor, Hirschman (1961 apud Dallabrida, 2011), o qual introduziu o conceito de linkagens (encadeamentos para diante e para trás), o que seria chave para a evolução teórica posterior. O autor parte do premissa de que o progresso econômico não ocorre ao mesmo tempo em toda a parte e nem da mesma forma e que, uma vez ocorrido e, que determinadas forças provocam uma concentração espacial do crescimento econômico, em torno dos pontos onde o processo se inicia. "Os chamados efeitos de encadeamento são os impactos que as diferentes atividades exercem sobre as demais, quando aumentam a sua produção, tanto para trás, como para frente, no processo produtivo".

Para Hirschman (1961 apud Lima; Simões, 2010), a força propulsora fo- 
mentadora da economia também deve ser o Estado e o mesmo deve prover a infraestrutura social necessária para impulsionar a atividade produtiva (serviços públicos, infraestrutura logística, legislação, entre outros) e elaborar uma estratégia de desenvolvimento, induzida e indutora, com a determinação das áreas prioritárias para o desenvolvimento.

Defende ainda, que é necessário o compromisso do estado com diversos projetos que tenham como objeto a política econômica e que tragam em si efeitos positivos sobre o fluxo de renda nas mais variadas áreas, e que é extremamente importante que se tenha planejamento e uma estratégia de desenvolvimento, posto que a medida que o desenvolvimento ocorre em setores específicos com maior concentração, acarreta o crescimento desigual e naturalmente surgem as tensões entre setores.

No presente artigo não há que se falar em desenvolvimento, governo, compras públicas, licitações e pregão eletrônico sem que se aborde a teoria evolucionista e a teoria das instituições. A economia evolucionária trata sistemas complexos que interagem em um mundo de diversidade, onde o papel central é de certo modo exercido pelas inovações. Nesse sentido, "o processo de crescimento e de desenvolvimento econômico está inserido em um processo de mudança estrutural, que permite que as mudanças tecnológicas e institucionais se alimentem reciprocamente (embora com timings diferentes), operando assim, as mudanças sociais" (CONCEIÇÃO, 2013).

Conceição (2013), afirma ainda que "para compreender o crescimento econômico e as instituições, o mesmo deve ser estudado dentro da noção evolutiva, uma vez que instituições, crescimento econômico e evolução caminham juntos e são conceitos indissociáveis".

Desse modo, para a corrente neo-schumpeteriana, tecnologia é definida como a incansável busca por novos produtos, novos procedimentos que acabam se difundindo num mesmo sistema. Aliás, é por essa razão que Nelson (2008, apud Conceição, 2009), vem propondo o conceito de "tecnologia social", "que articula as rotinas das firmas com as instituições e com a tecnologia". Na mesma direção, Lopes (2013) afirma que "as Instituições são primordiais ao desempenho, ao passo que são capazes de diminuir os problemas de utilização de mercado, agindo diretamente sobre os custos de transação".

Essa interação provoca , no decorrer do tempo, mudanças comportamentais, habituais e por conseguinte, nas normas e nas regras do jogo, estabelecendo um novo modelo institucional. Hodgson (2007 apud Conceição, 2013) "designa essa noção como de reconstitutive downward causation, que estabelece o nexo entre indivíduos, seus hábitos e crenças e as instituições, que determinam e são 
influenciadas pelos mesmos".

Conceição (2013), ainda observa que, segundo Hodgson (2007 apud Conceição, 2013), North (1990) e Nelson (1995), instituição pode ser definida como conjunto de normas, regras, hábitos e sua evolução.

Nesse mesmo sentido, North (1990) observa que:

[...] Partindo da preocupação com o desempenho Douglass North define instituições de forma bastante objetiva e focada. Ao representarem a estrutura de incentivos elas são imposições formais (tais como leis, regras, constituições etc...) e informais (normas de comportamento, convenções códigos de conduta etc...) da economia. Possuem importância fundamental porque, ao serem imposições criadas pelos seres humanos, acabam limitando suas interações (North, 1998, 1991). Além de incentivos, as instituições são restrições que moldam as escolhas individuais, mas ao mesmo tempo, são criação dos seres humanos que objetivam reduzir a incerteza em relação ao futuro e garantir um ambiente estável aos investimentos e a lucratividade do capital. Nas atividades diárias, os seres humanos se deparam com um conjunto de restrições que normalmente estão apresentadas na forma de leis ou de regras informais. Elas provêm de informações transmitidas socialmente, são parte da nossa cultura e interferem na forma como interpretamos o ambiente e influenciam na conduta dos indivíduos e das organizações [...] (NORTH 1990 apud LOPES, 2007).

De acordo ainda com as palavras de Conceição (2013), o Estado, tanto na amplitude nacional ou ainda que seja na regional, deixou de ser o dono do negócio para ser o administrador o qual deve ser parceiro e gestor. "Essa mudança institucional foi fundamental para o desenho da nova forma de ação estatal, que se tornou mais clara após a década de 90".

Não há ainda que se falar em pregões sem que seja abordada a tecnologia, a qual tem sido cada vez mais incluída nas teorias econômicas, porém quem desenvolveu uma teoria colocando a tecnologia como primordial ao desenvolvimento e a identificou como fundamental para a compreensão do desenvolvimento econômico, sobretudo em sistemas capitalistas, foi Joseph Schumpeter.

A Teoria Schumpeteriana, ainda que tenha sido desenvolvida na primeira metade do século XX, ainda hoje é atual, mesmo com as diversas mudanças que o sistema capitalista vem passando ao longo do tempo, principalmente quando se intensificou o processo de globalização da economia mundial (KUPFER, 2002 apud BRASIL, 2011).

Segundo Brasil (2011), na Teoria Schumpeteriana era entendido que "a verdadeira concorrência é aquela que busca a vantagem de custos e, uma melhor qualidade dos produtos, sendo que a inovação é a principal impulsionadora dessa competição, já que não basta apenas ser competitivo com relação ao preço".

A Teoria Schumpeteriana considera que a medida em que as empresas são 
maiores em um determinado mercado, consequentemente maior será a competição existente, pois é inquestionável a maior capacidade inovadora e de resistência das grandes empresas em relação às pequenas, uma vez que entre elas o ritmo de introdução de inovações seria mais intenso. Para Schumpeter, "o processo de inovação é basicamente endógeno ao sistema econômico e ocorreria em três fases distintas, mas complementares, as quais são: a) invenção; b) inovação e c) difusão" (SCHUMPETER, 1984 apud BRASIL, 2011).

É nesse mesmo sentido, que neste artigo serão tratadas as modalidades de licitação, pregão presencial e eletrônico, em especial o segundo, já que é possível destacar que, essa foi um marco para a inovação dos sistemas de aquisições públicas implantadas no Brasil.

\subsection{Licitações}

Com toda clareza, a implementação da modalidade pregão nas licitações brasileiras foi o marco inovativo para as compras públicas, uma vez que se pode tratar do assunto com maior transparência, ampliando competitividade, maior possibilidade de redução de custos, bem como o acesso a informação muito mais accessível a população, que é a maior beneficiária, uma vez que pode visualizar lances, a disputa toda por meio eletrônico, no caso da modalidade eletrônica.

Uma vez que foi regulamentado e de forma aparentemente tão eficaz e inovadora, tanto com relação aos procedimentos como com relação à economicidade, transparência e maior competitividade, passou a ser difundido aos órgãos públicos para que todos viessem a conhecer e, mais do que isso, adotar e passar a utilizá-lo, já que as modalidades anteriormente existentes estabelecidas pela Lei de Licitações (Lei n 8.666/93), não perderam sua aplicabilidade.

No entanto, as licitações eletrônicas têm tido maior visibilidade nos últimos anos, devido aos seus aspectos de redução de preço, maior agilidade, mais funcionalidade e sem contar a possibilidade de o certame ser muito mais competitivo, ao passo que a licitante não precisa se deslocar de sua empresa até o órgão para participar, é tudo realizado eletronicamente.

Tanto o pregão presencial como as demais modalidades de licitação presenciais, ainda podem ser aplicadas, porém o pregão em sua forma eletrônica deve preferencialmente ser utilizado e apenas na inviabilidade deste é que se aplica o presencial, essa é a regra para os órgãos federais, com relação aos estados e municípios dependem de sua regulamentação local, mas vale ressaltar, que embora as outras modalidades de licitação, que não eletrônica, estejam sendo muito 
menos utilizadas, ainda são legalmente cabíveis.

Por meio de emails entre outros meios eletrônicos, tem sido crescente a mobilização no sentido de que os administradores públicos divulguem suas ações e ampliem a transparência no que se referem aos atos dos gestores públicos. Desse modo, estão sendo introduzidas alterações operacionais nos governos, com uso intensivo e cada vez mais frequente de tecnologia da informação e da internet, objetivando respostas concretas a essa demanda contemporânea. (TRISTÃO, 2002 apud FARIA, 2011).

A transparência quando é tida como produção e um meio de divulgar informações, pode-se dizer que é o ícone para que se consiga combater a corrupção. Conceder transparência, constitui um dos principais requisitos da boa governança, bem como uma maneira de aproximar o Estado da sociedade, o que não deixa de ser uma função gestora o dever de ampliar o acesso do cidadão às informações sobre a gestão pública. (CULAU; FORTIS, 2006 apud FARIA, 2011).

É notável que o pregão, em especial o eletrônico, foi uma forma que o Governo encontrou de dar transparência aos atos públicos, uma vez que todo o certame ocorre online, a lista de lances, a disputa, após seu fechamento propostas são disponibilizadas, todos os participantes tomam ciência de todos os atos, tanto do agente público como dos demais fornecedores, outro aspecto bastante interessante é a não identificação dos participantes antes de finalizar o certame, isso também é um aspecto muito peculiar ao pregão eletrônico.

Com relação à estrutura de mercado, foi muito bem explanada por Faria (2011), quando afirma que, a estrutura de mercado do pregão eletrônico mais próximo é a competitiva, uma vez que possibilita participar da disputa fornecedores distantes, das mais diversas localidades, onde a barreira geográfica é basicamente eliminada e, que o licitante participa de sua própria empresa. Com isso, a disputa passa a ser muito mais competitiva, o que consequentemente, acarreta redução de preço.

Segundo Meirelles (2001), licitação pode ser conceituada como sendo o procedimento administrativo em que a Administração Pública seleciona a proposta mais vantajosa visando proporcionar igualdade de condições de participação aos que tiverem interesse, desde que atendam as regras estabelecidas antecipadamente por meio do edital de licitação, sempre com a devida observância dos princípios da eficiência e da moralidade.

Como no presente artigo só será estudada a modalidade pregão, não serão tratadas aqui definições e especificidades das demais modalidades. Boselli (2009) definiu o pregão da seguinte forma:

O pregão é uma modalidade de licitação, destinada à contratação de objetos comuns, 
de qualquer valor, em que a fase de composição se processa, por meio de propostas e por lances, apresentados em sessão pública, reduzindo as propostas iniciais, como se fosse um leilão reverso (BOSELLI, 2009, p. 35).

Boselli (2009) ressalta ainda que, essa modalidade é em quase sua totalidade diferente das demais, inclusive no que diz respeito à postura dos licitantes e dos agentes públicos; deve-se anular tudo o que se fazia e se sentia nas modalidades anteriores, é necessário que haja uma mudança significativa na postura das pessoas envolvidas com o certame e, principalmente por parte da Administração Pública. A utilização do pregão atinge a finalidade a que se propõe quando se consegue evitar decisões formalistas, que muitas vezes, na maioria dos casos acabam por reduzir o número de proposta em condições de serem aproveitadas no certame.

No que se refere ao pregão presencial e eletrônico, Cordeiro (2008, p. 131), lembrou muito bem quando escreveu que: "são comuns os equívocos da prática ao se atribuir a existência de duas modalidades distintas, a presencial e a eletrônica , quando o que se admite são duas formas distintas de se adotar a única modalidade prevista e disciplinada na Lei 10.520/02, norma geral do pregão".

A escolha por uma das duas modalidades era exclusivamente uma prerrogativa da Administração, até que a partir do Decreto Federal n. 5450, de 30 de maio de 2005 , elencou em seu art. $4^{\circ}, \S 1^{\circ}$ que:

Art. $4^{\circ}$. Nas licitações para aquisição de bens e serviços comuns será obrigatória a modalidade pregão, sendo preferencial a utilização da sua forma eletrônica.

$\S 1^{\circ}$. O pregão deve ser utilizado na forma eletrônica, salvo nos casos de comprovada inviabilidade, a ser justificada pela autoridade competente.

Essa passou a ser a regra para os órgãos federais, ficando a cargo dos estados e municípios regulamentarem em seus âmbitos o referido decreto, porém ainda assim fica a cargo da Administração Pública a definição da modalidade que melhor se adequa a sua aquisição de bem ou contratação de serviço, desde que devidamente justificada em caso de opção pela modalidade presencial.

Como bem observou Cordeiro (2008), sendo uma única modalidade, serão apresentadas no quadro 1 abaixo, as diferenças procedimentais e participativas na execução do pregão presencial e eletrônico.

Quadro 1. Principais diferenças entre o pregão presencial e o pregão eletrônico 


\begin{tabular}{|c|c|c|}
\hline & Pregão Presencial & Pregão Eletrônico \\
\hline $\begin{array}{c}\text { Forma de } \\
\text { Disputa }\end{array}$ & $\begin{array}{l}\text { Feita em sessão pública com } \\
\text { presença (física) dos participantes } \\
\text { em local determinado pelo órgão } \\
\text { licitante. }\end{array}$ & $\begin{array}{l}\text { Feita à distância em sessão pública, } \\
\text { por meio de sistema que promova a } \\
\text { comunicação pela internet. (presença } \\
\text { virtual) }\end{array}$ \\
\hline $\begin{array}{l}\text { Comunicação } \\
\text { entre pregoeiro } \\
\text { e licitante }\end{array}$ & $\begin{array}{l}\text { O pregoeiro dirige-se diretamente } \\
\text { e verbalmente ao licitante. Toda } \\
\text { comunicação entre eles é feita } \\
\text { em sessão pública, de forma } \\
\text { transparente a todos os participantes. }\end{array}$ & $\begin{array}{l}\text { Toda e qualquer comunicação entre } \\
\text { pregoeiro e licitante deve ser feita de } \\
\text { forma eletrônica, a fim de que todos } \\
\text { os licitantes tenham conhecimento. } \\
\text { É vedado o contato particular (por } \\
\text { exemplo: através do telefone ou outro } \\
\text { meio de comunicação), durante a } \\
\text { sessão pública. }\end{array}$ \\
\hline Credenciamento & $\begin{array}{l}\text { Os licitantes credenciam-se antes } \\
\text { da abertura do pregão, exibindo os } \\
\text { documentos de representação legal }\end{array}$ & $\begin{array}{l}\text { Somente participam os licitantes } \\
\text { previamente cadastrados e que } \\
\text { possuam senha de acesso ao sistema } \\
\text { eletrônico. }\end{array}$ \\
\hline Propostas & $\begin{array}{l}\text { A apresentação dos envelopes } \\
\text { contendo as propostas ao pregoeiro } \\
\text { é feita no início da sessão pública. }\end{array}$ & $\begin{array}{l}\text { Os licitantes possuem um prazo que } \\
\text { antecede a abertura do pregão para } \\
\text { apresentar (enviar) as propostas de } \\
\text { forma eletrônica. }\end{array}$ \\
\hline $\begin{array}{l}\text { Seleção das } \\
\text { empresas para a } \\
\text { fase de lances }\end{array}$ & $\begin{array}{l}\text { Participará da etapa de lances, o } \\
\text { autor da proposta de valor mais baixo } \\
\text { e todos aqueles com valor de } 10 \% \\
\text { acima. Não havendo pelo menos três } \\
\text { ofertas nas condições anteriores, } \\
\text { poderão os autores das melhores } \\
\text { propostas até o máximo de três, } \\
\text { participarem da etapa de lances. }\end{array}$ & $\begin{array}{l}\text { Todos os licitantes participarão da etapa } \\
\text { de lances, independentemente do valor } \\
\text { da proposta. }\end{array}$ \\
\hline Etapa de Lances & $\begin{array}{l}\text { Os lances serão oferecidos } \\
\text { obedecendo os critérios de menor } \\
\text { preço, ou seja, o lance ofertado pelo } \\
\text { licitante deve ser menor que o último } \\
\text { lance oferecido na licitação. }\end{array}$ & $\begin{array}{l}\text { O licitante somente poderá oferecer } \\
\text { lance inferior ao último por ele ofertado } \\
\text { e registrado pelo sistema. Verifica-se } \\
\text { portanto, que o licitante não é obrigado } \\
\text { a oferecer lance inferior ao menor lance } \\
\text { do pregão. }\end{array}$ \\
\hline $\begin{array}{l}\text { Forma para } \\
\text { apresentação } \\
\text { dos lances }\end{array}$ & $\begin{array}{l}\text { Os lances são verbais e sucessivos. } \\
\text { Não existe um prazo predeterminado } \\
\text { para cada lance ou para o término } \\
\text { desta etapa. Os licitantes são } \\
\text { incentivados pelo pregoeiro a } \\
\text { oferecer novas ofertas até que se } \\
\text { alcance o melhor preço. }\end{array}$ & $\begin{array}{l}\text { Os lances são encaminhados via } \\
\text { eletrônica. Em regra, a fase de lances } \\
\text { do pregão eletrônico obedece um tempo } \\
\text { "ordinário"(por exemplo: de } 30 \text { minutos) } \\
\text { em que todos os licitantes poderão } \\
\text { oferecer lances. Decorridos o prazo } \\
\text { ordinário, inicia-se automaticamente } \\
\text { o prazo randômico, após o que } \\
\text { transcorrerá período de tempo de Até } 30 \\
\text { minutos, aleatoriamente determinado } \\
\text { pelo sistema eletrônico, findo o qual } \\
\text { será automaticamente encerrada a } \\
\text { recepção de lances. }\end{array}$ \\
\hline Negociação & $\begin{array}{l}\text { Conhecida a melhor oferta (melhor } \\
\text { lance), o pregoeiro poderá negociar } \\
\text { diretamente com o proponente para } \\
\text { que seja obtido preço melhor }\end{array}$ & $\begin{array}{l}\text { Após o encerramento da etapa de } \\
\text { lances, o pregoeiro poderá encaminhar, } \\
\text { pelo sistema eletrônico, contraproposta } \\
\text { ao licitante que tenha apresentado lance } \\
\text { mais vantajoso, para que seja obtida } \\
\text { melhor proposta. }\end{array}$ \\
\hline
\end{tabular}




\begin{tabular}{|c|c|c|}
\hline & Pregão Presencial & Pregão Eletrônico \\
\hline Habilitação & $\begin{array}{l}\text { Encerrada a etapa de lances, o } \\
\text { pregoeiro procederá a abertura do } \\
\text { envelope contendo os documentos } \\
\text { de habilitação do licitante que } \\
\text { apresentou a melhor oferta. A } \\
\text { verificação da habilitação poderá ser } \\
\text { feita também através do sistema de } \\
\text { credenciamento. }\end{array}$ & $\begin{array}{l}\text { Concluída a etapa de lances, será } \\
\text { verificada, pelo pregoeiro, a habilitação } \\
\text { do licitante que tenha oferecido o melhor } \\
\text { preço, conforme as exigências contidas } \\
\text { no edital. A análise da habilitação } \\
\text { será feita: a) através de sistema de } \\
\text { credenciamento, b) via eletrônica; ou } \\
\text { c) através da documentação enviada } \\
\text { por fax. Necessariamente a forma de } \\
\text { apresentação da documentação deverá } \\
\text { estar prevista em edital. }\end{array}$ \\
\hline Recurso & $\begin{array}{l}\text { Concluída a habilitação e declarado } \\
\text { o vencedor do certame, o pregoeiro } \\
\text { abrirá a oportunidade para que os } \\
\text { interessados possam na sessão } \\
\text { pública manifestar imediata e } \\
\text { motivadamentea intenção de interpor } \\
\text { recurso. Havendo manifestação, } \\
\text { será concedido o prazo de três } \\
\text { dias para apresentação das contra- } \\
\text { razões, sendo-lhes assegurada } \\
\text { vista imediata dos elementos } \\
\text { indispensáveis à defesa dos seus } \\
\text { interesses. }\end{array}$ & $\begin{array}{l}\text { Declarado o vencedor, qualquer licitante } \\
\text { poderá durante a sessão pública, de } \\
\text { forma imediata e motivada, em campo } \\
\text { próprio, do sistema, manifestar sua } \\
\text { intenção de recorrer, quando lhe será } \\
\text { concedido o prazo de três dias para } \\
\text { apresentar as razões de recurso, } \\
\text { ficando os demais licitantes, desde } \\
\text { logo, intimados para, querendo, } \\
\text { apresentarem contra-razões em igual } \\
\text { prazo, que começará a contar do } \\
\text { término do prazo do recorrente, sendo- } \\
\text { lhes assegurada vista imediata dos } \\
\text { elementos indispensáveis à defesa dos } \\
\text { seus interesses. }\end{array}$ \\
\hline Adjudicação & $\begin{array}{l}\text { Não havendo manifestação de } \\
\text { intenção de recurso, o pregoeiro } \\
\text { adjudicará o objeto da licitação } \\
\text { ao vencedor. Havendo recurso, } \\
\text { a adjudicação será feita pela } \\
\text { autoridade competente. }\end{array}$ & $\begin{array}{l}\text { Não havendo manifestação de intenção } \\
\text { de recurso, o pregoeiro adjudicará } \\
\text { o objeto da licitação ao vencedor. } \\
\text { Havendo recurso, a adjudicação será } \\
\text { feita pela autoridade competente. }\end{array}$ \\
\hline Homologação & $\begin{array}{l}\text { A homologação do processo licitatório } \\
\text { é atribuição exclusiva da autoridade } \\
\text { competente. É imprescindível a } \\
\text { publicação deste ato na imprensa } \\
\text { oficial. }\end{array}$ & $\begin{array}{l}\text { A homologação do processo licitatório } \\
\text { é atribuição exclusiva da autoridade } \\
\text { competente. É imprescindível a } \\
\text { publicação deste ato na imprensa oficial. }\end{array}$ \\
\hline
\end{tabular}

Fonte: Peixoto, 2006

Verifica-se no quadro 1 acima descrito, que algumas diferenças ainda que indiretamente, levam o pregão eletrônico a ser mais propício a maior competitividade, por exemplo, quando a participação na etapa de lances, o número de participantes é ilimitado, ou seja, quantos enviarem propostas podem participar, independentemente do valor da proposta.

Por outro lado, no pregão eletrônico a etapa de lances, pode-se dizer restrita com relação ao tempo, já que, este é determinado em edital e, posteriormente, após o estabelecido, passa a ser randômico, ou seja, o sistema eletrônico que realiza o encerramento de forma aleatória, sem interferência de nenhuma das partes e, muitas vezes, o licitante ainda poderia ter a possibilidade de redução de seu preço. 


\section{METODOLOGIA}

Como nesse estudo, objetivou-se analisar a diferença na aplicabilidade do pregão presencial e do pregão eletrônico, mais especificamente com relação a tempo, preço e contratação local, considerou-se pertinente a demonstração das diferenças procedimentais, uma vez que, as mesmas podem estar relacionadas ou não, com o resultado final da presente análise.

Trata-se de uma pesquisa descritiva, quantitativa, com abordagem qualitativa, por meio de um estudo de caso, na Universidade Estadual de Mato Grosso do Sul (UEMS); a episteme da pesquisa segue a linha positivista.

Faz oportuno explicar que, a seleção da coleta de dados, uma vez que foi feita a análise no âmbito da UEMS, em processos realizados no ano de 2013 , a escolha desse ano se deu, pois possuía maior número de pregões presencias do que no ano de 2014, por exemplo, já que a Universidade realiza muito mais pregões eletrônicos do que presenciais. No ano de 2013 foram abertos apenas 09 (nove) para a modalidade de pregão presencial, sendo que somente um obteve resultado deserto, enquanto que foram abertos 73 (setenta e três) processos para a modalidade de pregões eletrônicos, como a escolha foi aleatória, não é possível saber se houveram resultados desertos ou fracassados.

Desse modo, foram selecionados oito pregões presenciais, que tiveram disputa e, do mesmo modo, apenas oito pregões eletrônicos, que também houve disputa. A base de dados pode até ser considerada pequena, porém é a que foi efetivamente realizada pela UEMS, isto no tocante aos pregões presenciais. Vale dizer que, os eletrônicos foram selecionados aleatoriamente e, que foram considerados os lotes, nesse caso foram analisados oito lotes de cada tipo de pregão.

Após a seleção dos processos, foi realizado o levantamento conforme apresentado no quadro $02 \mathrm{e}$, por meio de aritmética percentual simples, calculou-se o percentual de economia para cada certame. Verificou-se que a contratação ocorreu com empresas do Estado de Mato Grosso do Sul ou de outras localidades, bem como o tempo de execução do certame, a contar da realização do aviso de licitação até o resultado dessa, esse prazo foi considerado em dias corridos.

É importante ressaltar, que não foram consideradas quantidades a serem adquiridas ou serviços a serem contratados, posto que todos os processos foram contratações por valor global, para tanto foi considerado apenas o valor global do lote. Vale destacar ainda, que a comparação foi realizada entre o valor de referência publicado em edital e o valor final licitado, uma vez que o valor de referência é obtido por meio de pesquisa prévia, elaborada por servidores da instituição, por 
meio de consultas a empresas, sites, entre outros; isto para que não incorra em um resultado que pode não condizer com a realidade, conforme observado por Faria (2011), a seguir transcrito:

Embora estudos do governo apontem para um cenário favorável e otimista, ainda não há suficiente suporte metodológico para comprovar a superioridade técnica do pregão eletrônico. $\mathrm{O}$ atual método apenas calcula a economia adquirida no leilão, o que pode trazer um viés de mensuração, já que esta análise não leva em conta a estratégia dos fornecedores nesse tipo de disputa que geralmente começam com o preço elevado para que, caso não exista forte concorrência, eles consigam licitar o seu produto por um preço mais alto. Assim, comparar o preço de abertura do pregão com o preço de fechamento pode levar a uma amplitude de redução de preços maior que o ocorrido de fato (FARIA, 2011, p. 48).

É bastante comum em procedimentos licitatórios na modalidade pregão, especialmente nos eletrônicos, já que o número de participantes na etapa de lances é ilimitado, propostas com valores bem acima do de mercado, uma vez que o licitante tem a possibilidade de baixar o preço ofertado no momento da disputa, sendo esta uma estratégia utilizada pelos fornecedores e, caso não haja concorrentes eles acabam por vender pelo teto da referência estabelecida em edital e, ocorrendo isso, quem acaba não tendo nenhum benefício econômico na contratação é a Administração Pública.

Importante ressaltar também, que os nomes das empresas vencedoras do certame, embora sejam dados públicos, não serão neste trabalho divulgados, em virtude de não ter havido tempo hábil para requerer autorização de cada uma na divulgação de seus nomes e, também em virtude desta informação ser irrelevante para o estudo em questão. Desse modo, serão denominados apenas de Fornecedor $\mathrm{X}$ e, assim será divulgada apenas a localidade de sua sede, sendo o que importa para a presente pesquisa, uma vez que se deseja identificar se a contratação ocorreu no âmbito do Estado de MS ou de outra localidade.

\section{APRESENTAÇÃO DOS DADOS E RESULTADOS}

Nos quadros 2 e 3 , será apresentado o levantamento realizado na UEMS no ano de 2013, para o pregão presencial (PP) e pregão eletrônico (PE). 
ANÁLISE DO PREGÃO ELETRÔNICO E PRESENCIAL NA UNIVERSIDADE ESTADUAL

DE MATO GROSSO DO SUL

Quadro 2 - Pregão Presencial 2013

\begin{tabular}{|c|c|c|c|c|c|c|c|c|}
\hline $\begin{array}{c}\text { Modali } \\
\text { dade }\end{array}$ & $\begin{array}{l}\text { Material/ } \\
\text { Serviço }\end{array}$ & $\begin{array}{c}\text { Pu- } \\
\text { blic } \\
\text { Aviso }\end{array}$ & \begin{tabular}{c|} 
Public \\
Resul- \\
tado
\end{tabular} & $\begin{array}{l}\text { Tempo } \\
\text { (dias) }\end{array}$ & $\begin{array}{l}\text { Local } \\
\text { sede da } \\
\text { empresa } \\
\text { contra- } \\
\text { tada }\end{array}$ & $\begin{array}{l}\text { Valor de Refe- } \\
\text { rência }\end{array}$ & $\begin{array}{l}\text { Valor Lici- } \\
\text { tado }\end{array}$ & $\begin{array}{l}\text { Percen- } \\
\text { tual } \\
\text { economia }\end{array}$ \\
\hline PP001 & $\begin{array}{c}\text { Locação de } \\
\text { veículo de } \\
\text { passageiro } \\
\text { com motorista } \\
\end{array}$ & $29 / 01$ & $18 / 02$ & 19 & $\begin{array}{l}\text { Fornece- } \\
\text { dor X } \\
\text { Dourados } \\
\text { MS }\end{array}$ & $\begin{array}{c}\mathrm{R} \$ 150.250,76 \\
\mathrm{Km} \mathrm{5,31}\end{array}$ & $\begin{array}{c}\mathrm{R} \$ \\
135.820,80 \\
\mathrm{Km} \mathrm{4,80}\end{array}$ & $10 \%$ \\
\hline PP002 & $\begin{array}{c}\text { Confecção de } \\
\text { Pastas para } \\
\text { documentação } \\
\text { pessoal de } \\
\text { acadêmicos }\end{array}$ & $08 / 02$ & $27 / 02$ & 18 & $\begin{array}{l}\text { Fornece- } \\
\text { dor X } \\
\text { Dourados } \\
\text { MS }\end{array}$ & $\mathrm{R} \$ 5.880,00$ & $\mathrm{R} \$ 5.880,00$ & - \\
\hline PP003 & $\begin{array}{l}\text { Organização } \\
\text { de eventos }\end{array}$ & $04 / 03$ & $18 / 03$ & 13 & $\begin{array}{c}\text { Fornece- } \\
\text { dor X } \\
\text { Campo } \\
\text { Grande } \\
\text { MS }\end{array}$ & $\mathrm{R} \$ 60.000,00$ & $\mathrm{R} \$ 45.950,00$ & $24 \%$ \\
\hline PP004 & $\begin{array}{c}\text { Hospedagem } \\
\text { em hotel em } \\
\text { Dourados MS }\end{array}$ & $15 / 05$ & $29 / 05$ & 13 & $\begin{array}{l}\text { Fornece- } \\
\text { dor X } \\
\text { Dourados } \\
\text { MS }\end{array}$ & $\mathrm{R} \$ 30.390,90$ & $\mathrm{R} \$ 25.194,00$ & $17 \%$ \\
\hline PP005 & $\begin{array}{c}\text { Carteirinha } \\
\text { tombamento } \\
\text { para biblioteca }\end{array}$ & $07 / 06$ & $24 / 06$ & 16 & $\begin{array}{l}\text { Fornece- } \\
\text { dor X } \\
\text { Dourados } \\
\text { MS }\end{array}$ & $\mathrm{R} \$ 3.200,00$ & $\mathrm{R} \$ 2.800,00$ & $12 \%$ \\
\hline PP007 & $\begin{array}{c}\text { Contratação } \\
\text { de empresa } \\
\text { para reparo de } \\
\text { nobreak, com } \\
\text { fornecimento } \\
\text { de baterias e } \\
\text { calibração }\end{array}$ & $05 / 09$ & $20 / 09$ & 14 & $\begin{array}{l}\text { Fornece- } \\
\text { dor X } \\
\text { Dourados } \\
\text { MS }\end{array}$ & $\mathrm{R} \$ 1.362,00$ & $\mathrm{R} \$ 1.350,00$ & $1 \%$ \\
\hline PP008 & $\begin{array}{l}\text { Organização } \\
\text { de eventos }\end{array}$ & $10 / 10$ & $25 / 10$ & 14 & $\begin{array}{c}\text { Fornece- } \\
\text { dor X } \\
\text { Campo } \\
\text { Grande } \\
\text { MS } \\
\end{array}$ & $\mathrm{R} \$ 67.244,73$ & $\mathrm{R} \$ 41.000,00$ & $39 \%$ \\
\hline PP009 & $\begin{array}{c}\text { Locação de } \\
02 \text { veículos } \\
\text { de passageiro } \\
\text { com motorista }\end{array}$ & $13 / 11$ & $28 / 11$ & 14 & $\begin{array}{l}\text { Fornece- } \\
\text { dor X } \\
\text { Dourados } \\
\text { MS }\end{array}$ & $\begin{array}{c}\mathrm{R} \$ 181.328,28 \\
\mathrm{Km} 5,56\end{array}$ & $\begin{array}{c}\mathrm{R} \$ 81.206,37 \\
\mathrm{Km} 2,49\end{array}$ & $55 \%$ \\
\hline
\end{tabular}

Fonte: Elaborado pelos pesquisadores a partir dos dados da UEMS 
Quadro 3. Pregão Eletrônico 2013

\begin{tabular}{|c|c|c|c|c|c|c|c|c|}
\hline $\begin{array}{l}\text { Modali } \\
\text { dade }\end{array}$ & $\begin{array}{l}\text { Material/ } \\
\text { Serviço }\end{array}$ & $\begin{array}{c}\text { Public } \\
\text { aviso } \\
2013\end{array}$ & $\begin{array}{c}\text { Public } \\
\text { Resul- } \\
\text { tado } \\
2013\end{array}$ & $\begin{array}{l}\text { Tempo } \\
\text { (dias) }\end{array}$ & $\begin{array}{l}\text { Local sede } \\
\text { da empresa } \\
\text { contratada }\end{array}$ & $\begin{array}{l}\text { Valor de Re- } \\
\text { ferên } \\
\text { cia }\end{array}$ & $\begin{array}{c}\text { Valor } \\
\text { Licitado }\end{array}$ & $\begin{array}{l}\text { Percentual } \\
\text { de econo- } \\
\text { mia }\end{array}$ \\
\hline PE001 & $\begin{array}{l}\text { Serviço } \\
\text { de apoio } \\
\text { adminis- } \\
\text { trativo } \\
\text { UAB }\end{array}$ & $14 / 01$ & $30 / 01$ & 15 & $\begin{array}{l}\text { Fornecedor } \\
\text { X - Campo } \\
\text { Grande -MS }\end{array}$ & $\begin{array}{c}R \$ \\
103.543,72\end{array}$ & $\begin{array}{c}\mathrm{R} \$ \\
98.000,00\end{array}$ & $5 \%$ \\
\hline PE002 & $\begin{array}{l}\text { Projetores } \\
\text { multimídia }\end{array}$ & $14 / 01$ & $04 / 02$ & 20 & $\begin{array}{l}\text { Fornecedor X } \\
\text { - São José do } \\
\text { Rio Preto- SP }\end{array}$ & $R \$ 13.891,84$ & $\mathrm{R} \$ 8.600,00$ & $38 \%$ \\
\hline PE003 & \begin{tabular}{|c|} 
Condicio- \\
nador de \\
ar 24.000 \\
BTUs
\end{tabular} & $28 / 01$ & $18 / 02$ & 20 & $\begin{array}{c}\text { Fornecedor } \\
\text { X - Curitiba } \\
\text { - PR }\end{array}$ & $\mathrm{R} \$ 4.560,00$ & $\mathrm{R} \$ 4.549,00$ & $0,3 \%$ \\
\hline $\begin{array}{l}\text { PE004 } \\
\text { (pregão } \\
\text { com dois } \\
\text { lotes) }\end{array}$ & \begin{tabular}{|c|} 
Centrifuga \\
refrige- \\
rada de \\
mesa com \\
tubos de \\
alta velo- \\
cidade \\
\end{tabular} & $29 / 01$ & $\begin{array}{c}05 / 03 \\
\text { (com re- } \\
\text { curso) }\end{array}$ & 43 & $\begin{array}{l}\text { Fornecedor } \\
\text { X - Diadema } \\
\text { - SP }\end{array}$ & $R \$ 20.000,00$ & $\begin{array}{c}R \$ \\
15.600,00\end{array}$ & $22 \%$ \\
\hline PE004 & $\begin{array}{l}\text { Ultra- } \\
\text { freezer } \\
\text { vertical } \\
\left(-80^{\circ} \mathrm{C}\right)\end{array}$ & $29 / 01$ & $\begin{array}{c}04 / 03 \\
\text { (com re- } \\
\text { curso) }\end{array}$ & 42 & $\begin{array}{c}\text { Fornecedor X } \\
\text { - Piracicaba- } \\
\text { SP }\end{array}$ & $\mathrm{R} \$ 30.000,00$ & $\begin{array}{c}R \$ \\
28.498,00\end{array}$ & $5 \%$ \\
\hline PE010 & $\begin{array}{l}\text { Micros- } \\
\text { cópio } \\
\text { biológico } \\
\text { binocular }\end{array}$ & $18 / 03$ & $\begin{array}{l}21 / 05 \\
\text {-com } \\
\text { altera- } \\
\text { ções }\end{array}$ & 62 & $\begin{array}{l}\text { Fornecedor } \\
\text { X - São Pau- } \\
\text { lo SP }\end{array}$ & $\mathrm{R} \$ 29.191,68$ & $\begin{array}{c}R \$ \\
21.799,96\end{array}$ & $25 \%$ \\
\hline PE 032 & $\begin{array}{l}\text { Micro- } \\
\text { computa } \\
\text { dores }\end{array}$ & $08 / 06$ & $07 / 08$ & 58 & $\begin{array}{l}\text { Fornecedor X } \\
\text { - Florianópolis } \\
\text { - SC }\end{array}$ & $\begin{array}{c}R \$ \\
199.084,00\end{array}$ & $\begin{array}{c}\mathrm{R} \$ \\
154.349,74 \\
\end{array}$ & $22 \%$ \\
\hline PE 016 & Pneus & $10 / 04$ & $03 / 05$ & 22 & $\begin{array}{l}\text { Fornecedor X } \\
\text { - Osasco-SP }\end{array}$ & $\mathrm{R} \$ 12.651,20$ & $\begin{array}{c}\mathrm{R} \$ \\
10.453,60 \\
\end{array}$ & $17 \%$ \\
\hline
\end{tabular}

Fonte: Elaborado pelos pesquisadores a partir dos dados da UEMS

Como é possível verificar nos quadros 2 e 3, das licitações realizadas pela UEMS, o pregão presencial é o que mais apresenta contratações no âmbito do Estado de Mato Grosso do Sul, já que dos realizados, 100\% das contratações foram efetivadas por empresas com sede no Estado; já nos pregões eletrônicos apenas uma das empresas possui sede no Estado de MS, obviamente esta análise, com relação aos eletrônicos foi amostral, portanto não cabe aqui afirmar que nenhuma empresa no Estado de MS vence pregão eletrônico no âmbito da UEMS, mas é possível assegurar que a proporção é consideravelmente menor, em comparação as modalidades presenciais.

Não serão identificadas aqui as causas dessa diferença, mas é evidente que parte dela se dá devido a própria forma com que estão estabelecidos em ambos os procedimentos, conforme já demonstrado no quadro 1. 
Com relação ao preço e a economicidade de cada modalidade, será apresentado no quadro 4, a diferença entre um e outro para melhor visualização.

Figura 4. Demonstrativo do Percentual de Economia

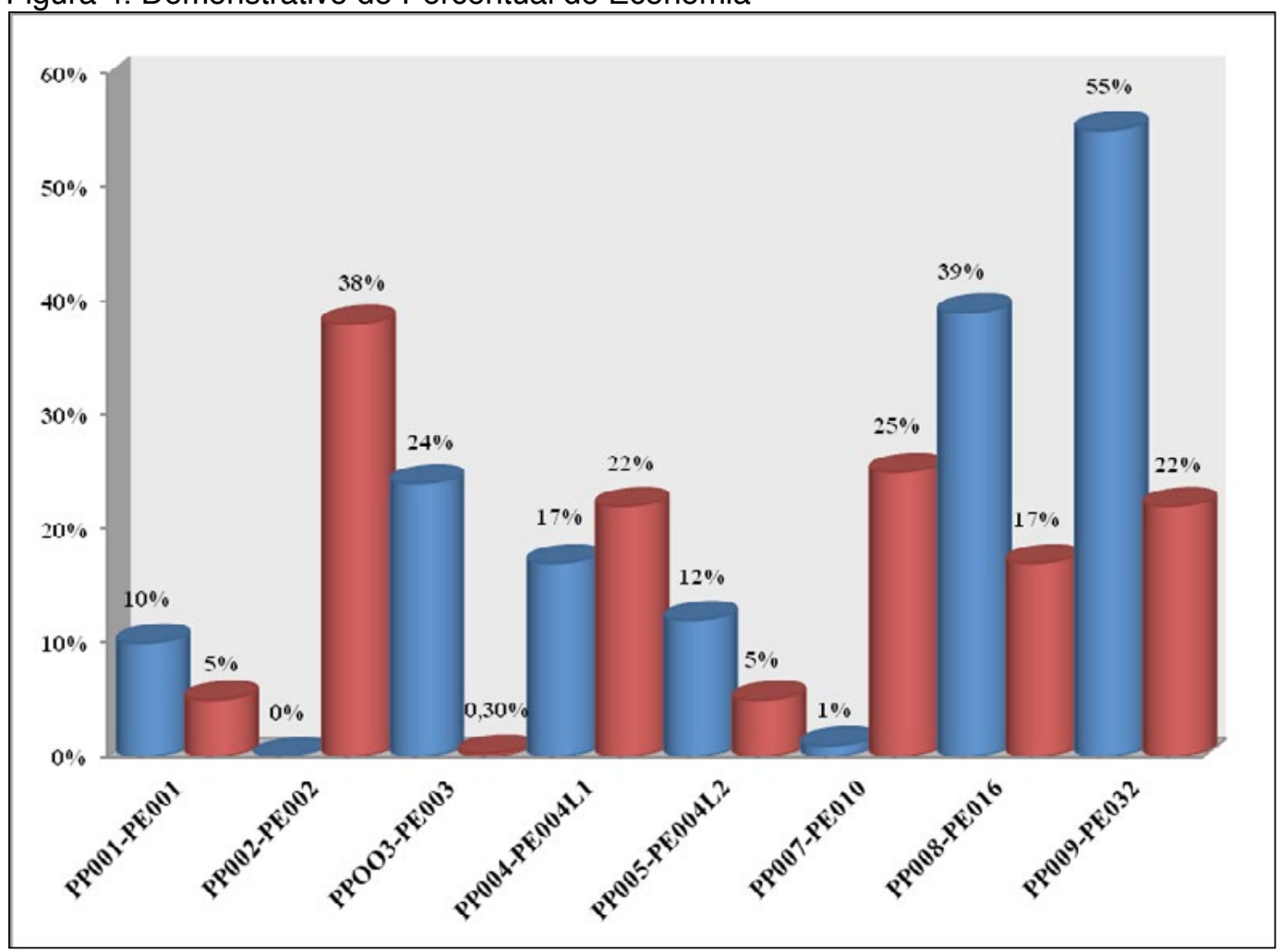

Fonte: Elaborado pela pesquisadora a partir dos dados da UEMS

PP - Pregão Presencial

PE - Pregão Eletrônico

É fato que esta análise deve também ser realizada caso a caso, já que cada processo possui suas especificidades, bem como vale lembrar que os percentuais foram realizados entre o valor de referência e o valor licitado e, não entre o pregão eletrônico e o presencial. Desse modo, o quadro 4 demonstra o percentual de desconto individual de cada processo; no entanto, é fato que no ano de 2013, nas amostras selecionadas, o pregão presencial teve maior percentual de desconto na maioria dos certames, bem como com percentuais mais expressivos.

De modo geral, esse não é o resultado esperado, uma vez que o pregão eletrônico tem diversas possibilidades favoráveis para que se conclua a licitação com maior economia do que no pregão presencial, a começar pela possibilidade de maior competitividade. No entanto, não é possível afirmar se esse foi um caso 
isolado ocorrido no ano de 2013, mais especificamente nas amostras utilizadas. O que se pode observar é que com o pregão presencial da UEMS, nas amostras selecionadas no ano de 2013, obteve-se maior desconto na maioria dos certames.

Com relação ao tempo, utilizou-se uma média aritmética simples, onde se somam todos e divide-se pela quantidade de pregões, lembrando que esses dias foram considerados o período entre o aviso da licitação e o resultado da mesma, temse que o pregão eletrônico se realiza, numa média de 35 dias e o pregão presencial numa média de 15 dias, resultado este que também não condiz com o esperado, posto que o pregão eletrônico tem como um de seus objetivos ser mais ágil.

No entanto, embora não se pesquisou as causas desse resultado, uma das hipóteses desse resultado se deu devido ao fato de a maioria dos licitantes serem de outros estados e, conforme verificado nos editais, foram exigidas documentações originais dos vencedores, nesse casso é necessário aguardar o tempo de envio dessa documentação, enquanto que nos presenciais tudo se resolve no próprio certame. Outro fato que pode ter alterado nesse decurso de tempo é, que nas amostras dos pregões eletrônicos utilizadas, dois dos processos obtiveram entraves, posto que em um houve recurso, o que aumenta o prazo de finalização e, em outro houve alterações no edital, o que também acarreta aumento no prazo de finalização.

\section{CONSIDERAÇÕES FINAIS}

Diante de todo o exposto e, principalmente com foco na Teoria da Inovação de Schumpeter e na Teoria das Instituições e Evolucionista, percebe-se que a modalidade pregão foi o grande avanço governamental com relação às compras públicas, de modo que conseguiu introduzir na Administração Pública, uma modalidade completamente diversa das anteriormente estabelecidas, que tem sido capaz de atender a demanda a contento e em melhor grau de eficiência e agilidade.

É fato que ainda nessa modalidade, em especial deve ser levada em conta a idoneidade do agente público, bem como a dos fornecedores, para que não seja deturpado todo o sistema. Porém, ao menos com essa modalidade, em especial a eletrônica, tornou-se muito mais transparente os certames realizados pela Administração Pública, o que possibilitou também uma maior interação da população com o serviço público.

$\mathrm{Na}$ análise comparativa, tem-se que, embora a legislação aponte preferência ao pregão eletrônico, essa preferência ainda deve ser questionada, pois não parece muito interessante que a maioria das contratações realizadas por um determinado órgão público, seja quase que em sua totalidade revertida à outra localidade, isso só quando for tratado de desenvolvimento local e regional. Muito mais interessante seria 
que os recursos circulassem no próprio município, ou ao menos no próprio estado.

Porém, sugere-se que estudos futuros possam demonstrar o quanto se contrata o pregão eletrônico no âmbito do Estado, uma vez que nesse estudo a análise foi amostral e não permite identificar um balanço anual e, a partir daí buscar identificar o motivo dessa não contratação local. Faltariam políticas de incentivo a participação das empresas locais nos certames eletrônicos, seria falta de informação ou talvez diferença tributária que as empresas locais não conseguem ser competitivas com outros estados, que porventura venham a possuir tributação diferenciada. São perguntas que não compete a este estudo responder, mas que podem futuramente ser trabalhadas e, aqui fica apenas a certeza de que, nas amostras estudadas, sem nenhuma dúvida, o pregão presencial tem muito mais possibilidade de fomentar a circulação local da moeda do que o pregão eletrônico e, que não necessariamente ele seja finalizado com menor desconto, do que na modalidade eletrônica

\section{REFERÊNCIAS}

Boselli, P. (2009) Pregão: capacitação para pregoeiros e licitantes. Curitiba: Negócios Públicos.

Brasil, M.V.O.; Nogueira, C.A.G.; Forte, S.H.A.C. (2011) Schumpeter e o Desenvolvimento Tecnológico: uma visão aplicada às Pequenas e Médias Empresas (PMEs). Revista de Ciências da Administração. Florianópolis, v.13, n. 29, p.38-62, jan./abr., Disponível em: <https://periodicos.ufsc.br/index.php/ adm/article/view/2175-8077.2011v13n29p38>. Acesso em: 26 nov. 2015.

BRASIL. (2000) Decreto 3.555, de 8 de agosto de 2000. Aprova o Regulamento para a modalidade de licitação denominada pregão, para aquisição de bens e serviços comuns. Diário Oficial (da República Federativa do Brasil). Disponível em: <http:// www.planalto.gov.br/ccivil_03/decreto/d3555.htm>. Acesso em: 26 nov. 2015.

BRASIL.(2005) Decreto n. 5.450, de 31 de maio de 2005. Regulamenta o pregão na forma eletrônica, para aquisição de bens e serviços comuns, e dá outras providências. Diário Oficial (da República Federativa do Brasil). Disponível em: <http://www.planalto.gov.br/ccivil_03/_ato2004-2006/2005/decreto/ d5450.htm>. Acesso em: 26 nov. 2015.

BRASIL.(2002) Lei 10.520, de 17 de julho de 2002. Institui, no âmbito da União, Estados, Distrito Federal e Municípios, nos termos do art. 37, inciso XXI, da Constituição Federal, modalidade de licitação denominada pregão, para aquisição de bens e serviços comuns, e dá outras providências. Diário Oficial (da República Federativa do Brasil). Disponível em: <http://www.planal- 
to.gov.br/ccivil_03/leis/2002/L10520.htm>. Acesso em: 26 nov. 2015.

Conceição, O.A.C. (2013) A economia brasileira e as mudanças estruturais pós anos 1980: novo paradigma, novas instituições ou novo desenvolvimentismo? Revista Economia \& Tecnologia (RET), v. 9, n. 1, p. 117-136. Disponível em: <http://www.economiaetecnologia.ufpr.br/revista/Volume\%209\%20 n\%201/Versao\%20final.pdf>. Acesso em: 11 nov. 2015.

Conceição, O.A.C. (2009) Instituições e crescimento econômico: da "tecnologia social" de Nelson à "Causalidade Vebleriana" de Hodgson. XXXVII Encontro Nacional de Economia. ANPEC. Disponível em: <http://www.anpec.org.br/ novosite/br/encontro-2009>. Acesso em: 04 nov. 2015.

Cordeiro, V. (2008) Formação e capacitação de pregoeiros. Curitiba: Negócios Públicos.

Crecencio, V.L. (2002) A Lei 10.520 de 2002. Institui o pregão uma visão prática e operacional. Portal de E-GOV inclusão digital e sociedade do conhecimento. Disponível em: <http://www.egov.ufsc.br/portal/conteudo/lei-10520-de2002-que-institui-o-preg\%C3\%A3o-uma-vis\%C3\%A3o-pr\%C3\%A1tica-e -operacional>. Acesso em: 14 nov. 2015.

Dallabrida, V.R; Deschamp, M.V.; Schimalsk, M.B. et al. (2011) Aportes teórico metodológicos sobre a dimensão espacial do desenvolvimento: uma contribuição. Revista Desenvolvimento Regional em Debate. Universidade do Contestado. Disponível em: <http://www.unc.br/mestrado/docs/ARTIGO -APORTES-TEORICOS-DRd-2012.pdf>. Acesso em: 09 nov. 2015.

Faria, E.R.; Ferreira, M.A.M.F.; Santos, L.M. (2011) Pregão eletrônico versus pregão presencial: estudo comparativo de redução de preços e tempo. Revista de Contabilidade do Mestrado em Ciências da UERJ, Rio de Janeiro, v. 16, n.1, p. 47-62. Disponível em: <http://www.e-publicacoes.uerj.br/index.php/ rcmccuerj/article/view/5478>. Acesso em: 05 nov. 2015.

Furtado, L.R. (2007) Curso de Direito Administrativo. Belo Horizonte: Fórum Ltda. Gasparini, D. (1995) Direito Administrativo. 4 ed. São Paulo: Saraiva, 1995.

Lima, A.C.C.; Simões, R.F. (2010) Teorias clássicas do desenvolvimento e suas implicações de política econômica: o caso do Brasil. Revista de Desenvolvimento Econômico - RDE. Programa de Doutorado em Economia da Universidade Federal de Minas Gerais, 2010.

Lopes, H.C. (2013) Instituições e crescimento econômico: os modelos teóricos de Thorstein Veblen e Douglass North. Revista de Economia Política, v. 33, n 4, p. 619-637. Disponível em: <http://www.scielo.br/pdf/rep/v33n4/v33n4a04. 
pdf $>$. Acesso em: 11 nov. 2015.

Lopes, L.T. (2007) Modelo de Big Push e externalidades intersetoriais: uma análise de cointegração da economia brasileira. Anais do XXXV Encontro Nacional de Economia - ANPEC. USP. São Paulo. Disponível em: <http://www.anpec. org.br/encontro2007/artigos/A07A102.pdf>. Acesso em: 31 out. 2015.

Meirelles, H.L.(2001) Direito Administrativo Brasileiro. 26. ed. São Paulo: Malheiros.

Peixoto, A.M. (2006) Pregão presencial e eletrônico: comentários à Lei Federal $n^{\circ}$ 10520, de 17 de julho de 2002, e legislação comparada. Campinas: Prime. 